\title{
Reduced cardiorespiratory fitness, low physical activity and an urban environment are independently associated with increased cardiovascular risk in children
}

\author{
S. Kriemler • S. Manser-Wenger • L. Zahner • \\ C. Braun-Fahrländer • C. Schindler • J. J. Puder
}

Received: 6 February 2008 /Accepted: 19 May 2008 / Published online: 17 June 2008

(C) Springer-Verlag 2008

\begin{abstract}
Aims/hypothesis To assist in the development of preventive strategies, we studied whether the neighbourhood environment or modifiable behavioural parameters, including cardiorespiratory fitness (CRF) and physical activity (PA), are independently associated with obesity and metabolic risk markers in children.

Methods We carried out a cross-sectional analysis of 502 randomly selected first and fifth grade urban and rural Swiss schoolchildren with regard to CRF, PA and the neighbourhood (rural vs urban) environment. Outcome measures included BMI, sum of four skinfold thicknesses, homeostasis model assessment of insulin resistance
\end{abstract}

S. Kriemler and S. Manser-Wenger contributed equally to this study.

S. Kriemler $\cdot$ L. Zahner

Institute of Exercise and Health Sciences,

University of Basel,

Basel, Switzerland

S. Manser-Wenger

Division of Endocrinology and Diabetes and Clinical Nutrition,

University of Basel,

Basel, Switzerland

C. Braun-Fahrländer $\cdot$ C. Schindler

Institute of Social and Preventive Medicine,

University of Basel,

Basel, Switzerland

J. J. Puder $(\bowtie)$

Division of Endocrinology, Diabetes and Metabolism,

University of Lausanne,

BH-19, CHUV, Rue du Bugnon 46,

CH-1011 Lausanne, Switzerland

e-mail: jardena.puder@chuv.ch
(HOMA-IR) and a standardised clustered metabolic risk score.

Results CRF and PA (especially total PA, but also the time spent engaged in light and in moderate and vigorous intensity PA) were inversely associated with measures of obesity, HOMA-IR and the metabolic risk score, independently of each other, and of sociodemographic and nutritional parameters, media use, sleep duration, BMI and the neighbourhood environment (all $p<0.05$ ). Children living in a rural environment were more physically active and had higher CRF values and reduced HOMA-IR and metabolic risk scores compared with children living in an urban environment (all $p<0.05$ ). These differences in cardiovascular risk factors persisted after adjustment for CRF, total PA and BMI. Conclusions/interpretation Reduced CRF, low PA and an urban environment are independently associated with an increase in metabolic risk markers in children.

Trial registration: isrctn.org 15360785

Funding: The study was funded by the Federal office of Sports (Magglingen, Switzerland), the Swiss National Science Foundation (grant nos 3234-069271 and PMPDB-114401) and the Diabetes Foundation of the Region of Basel.

Keywords Aerobic fitness - Cardiovascular disease - Child . Inflammation · Insulin resistance · Metabolic syndrome ·

Obesity Physical activity Physical fitness

\begin{tabular}{ll}
\multicolumn{2}{l}{ Abbreviations } \\
CRF & cardiorespiratory fitness \\
HOMA-IR & $\begin{array}{l}\text { homeostasis model assessment of insulin } \\
\text { resistance }\end{array}$ \\
PA & physical activity
\end{tabular}




\section{Introduction}

Childhood obesity has substantially increased over the last decades and is strongly associated with increases in cardiovascular risk factors such as high blood pressure, dylipidaemia and insulin resistance [1]. Childhood levels of various cardiovascular risk factors can predict adult values [2] and the extent of the atherosclerotic process, independently of the current risk [3]. The causes of childhood obesity and increased cardiovascular risk are multifactorial and include genetic predisposition, intrauterine factors, the early postpartal period and cultural, socioeconomic and environmental variables, as well as current modifiable behavioural parameters [4]. Examples of the latter are changes in nutritional behaviour [5,6], decreased sleep duration [4] and an increase in sedentary behaviour [7]. Also included in this list are a decrease in physical activity (PA) or reduced cardiorespiratory fitness (CRF) [8, 9], which although partially genetically determined is also influenced by a lack of appropriate exercise [10].

In healthy children, the relationship of CRF or PA with cardiovascular risk factors is not only mediated by obesity $[8,11-14]$. As in obesity, reduced levels of CRF and PA in adults are both associated with increased risks of cardiovascular and total mortality $[15,16]$.

Unfortunately, many studies that have aimed to prevent an increase in obesity or cardiovascular risk in children, on a school- or family-based level, have only yielded modest success [17]. Thus, it remains controversial as to which of the potential underlying variables should be targeted and how they could be efficiently modified. For example, exclusively targeting behaviour within the school and/or family might be too limited an approach to effect significant and sustained changes [17]. Based on reports that the neighbourhood environment is associated with PA, some authors have postulated that the neighbourhood environment plays a significant role in determining lifestyle behaviour and cardiovascular risk [18-21].

The objective of this study was to examine a populationbased sample of children for associations of CRF and measures of PA with obesity and cardiovascular risk factors that were independent of sociodemographic and other behavioural lifestyle parameters. We also investigated whether the neighborhood environment had an independent effect on CRF, PA or metabolic risk markers.

\section{Methods}

Participants and study design We present baseline data from the Kinder-Sportstudie (KISS) study, a randomised controlled trial investigating the effects of a PA intervention in schoolchildren on PA, CRF and obesity. The aim, design and assessment of the predictor and outcome variables have been previously described in detail [22]. Briefly, 15 schools with a total of 28 classes were randomly selected from two provinces in Switzerland after stratification by the type of neighbourhood environment (urban vs rural), grade (first and fifth grade) and ethnicity to be representative of Swiss children with respect to sociodemographic status and BMI (Table 1). Parental ethnic background was divided into three categories: both parents Swiss or of Central European origin, one parent from a foreign ethnic background (16\%) or both parents from a foreign ethnic background (27\%). Of those classified as being from a foreign ethnic background, $38 \%$ were from the former Yugoslavia, 26\% from Italy or Spain, $10 \%$ from Sri Lanka, $8 \%$ from Turkey, and the remainder were from the Middle East, Asia or South America.

The present cross-sectional study was performed in late summer/early autumn of 2005. Of 535 children, 502 (94\%) agreed to participate and attended the examination days. Of these, CRF data were available for $502(100 \%)$, anthropometry for 497 (99\%), socioeconomic data for 480 (96\%), data regarding sedentary behaviour for 489 (97\%), selfreported nutritional information for 437 (87\%), valid accelerometer data for $391(78 \%)$ and valid blood analyses for $367(73 \%)$. BMI and mean blood pressure were not different between the children with and without valid accelerometer data or with and without valid blood analyses (all $p>0.1$ ). Informed consent for completion of the questionnaires and for all measurements was provided by each child and a parent. The study was approved by the ethics committees of the University of Basel and the ETH of Zürich (Eidgenössische Technische Hochschule Zürich, also known as the Swiss Federal Institute of Technology), as well as by the Cantonal Ethical Committee of Aargau, Switzerland.

Measurements Standing height, body weight, blood pressure, waist circumference and skinfold thicknesses at four sites were measured as previously described [22]. BMI, skinfold thickness (sum of the four skinfold thicknesses), and waist circumference were used as measures of obesity. Waist circumference and skinfold thicknesses were measured by the same two investigators (S. Kriemler, J. J. Puder) for all children.

Assays Overnight fasting blood samples were drawn in the morning, from the antecubital vein, for measurement of glucose, insulin and lipids. The blood was collected in vacutainers, which were immediately put on ice and immediately transported to a single hospital, where it was analysed within a few hours after sampling [22]. The CVs and characteristics of these assays have been reported previously [22]. 
Table 1 Baseline characteristics of the participants

\begin{tabular}{|c|c|c|c|c|c|c|}
\hline \multirow[t]{2}{*}{ School grade } & \multicolumn{2}{|l|}{ First grade } & \multicolumn{2}{|l|}{ Fifth grade } & \multirow{2}{*}{$\begin{array}{l}p \text { value for } \\
\text { difference } \\
\text { between first } \\
\text { and fifth } \\
\text { grade }\end{array}$} & \multirow{2}{*}{$\begin{array}{l}p \text { value for } \\
\text { difference between } \\
\text { boys and girls }\end{array}$} \\
\hline & Boys $(n=114)$ & Girls $(n=119)$ & Boys $(n=129)$ & Girls $(n=140)$ & & \\
\hline Age (years) & $7.0 \pm 0.3$ & $6.8 \pm 0.3$ & $11.2 \pm 0.2$ & $11.1 \pm 0.5$ & $<0.0001$ & 0.0007 \\
\hline Height $(\mathrm{cm})$ & $123.0 \pm 5$ & $122.2 \pm 5.6$ & $146.4 \pm 6.9$ & $145.5 \pm 7.1$ & $<0.0001$ & NS \\
\hline Weight (kg) & $24.5 \pm 4.4$ & $24.2 \pm 4.5$ & $38.6 \pm 8.4$ & $38.4 \pm 8.0$ & $<0.0001$ & NS \\
\hline $\mathrm{BMI}^{\mathrm{a}}\left(\mathrm{kg} / \mathrm{m}^{2}\right)$ & $15.9(14.9-16.6)$ & $15.8(14.5-17.4)$ & $17.1(16.0-19.3)$ & $17.6(16.2-19.5)$ & $<0.0001$ & NS \\
\hline $\begin{array}{l}\text { Sum of four skinfold } \\
\text { thicknesses }{ }^{\mathrm{a}}(\mathrm{mm})\end{array}$ & $23.4(19.9-27.5)$ & $26.5(22.2-34.3)$ & $26.6(22.5-38.9)$ & $34.9(27.8-46.1)$ & $<0.0001$ & $<0.0001$ \\
\hline $\begin{array}{l}\text { Waist circumference } \\
(\mathrm{cm})\end{array}$ & $55.2 \pm 5.8$ & $54.7 \pm 5.4$ & $64.1 \pm 7.4$ & $62.7 \pm 6.5$ & $<0.0001$ & 0.07 \\
\hline $\begin{array}{l}\text { Pubertal stage } \\
\text { (\% prepubertal) }\end{array}$ & 100 & 100 & 68 & 36 & 0.0001 & $<0.0001$ \\
\hline $\begin{array}{l}\text { Systolic blood pressure } \\
(\mathrm{mmHg})\end{array}$ & $100 \pm 7$ & $101 \pm 8$ & $106 \pm 8$ & $105 \pm 8$ & $<0.0001$ & NS \\
\hline $\begin{array}{l}\text { Diastolic blood } \\
\text { pressure }(\mathrm{mmHg})\end{array}$ & $59 \pm 7$ & $60 \pm 7$ & $64 \pm 7$ & $64 \pm 8$ & $<0.0001$ & NS \\
\hline HOMA-IR ${ }^{\mathrm{a}}$ & $1.0(0.7-1.4)$ & $1.0(0.7-1.2)$ & $1.5(1.0-2.0)$ & $1.7(1.2-2.3)$ & $<0.0001$ & NS \\
\hline Insulin $^{\mathrm{a}}(\mathrm{pmol} / \mathrm{l})$ & $34.4(25.8-48)$ & $36.6(27.1-45.6)$ & $51.7(35.0-66)$ & $57.0(43.2-77.3)$ & $<0.0001$ & 0.02 \\
\hline Glucose $(\mathrm{mmol} / \mathrm{l})$ & $4.5 \pm 0.4$ & $4.4 \pm 0.4$ & $4.7 \pm 0.4$ & $4.6 \pm 0.4$ & $<0.0001$ & 0.008 \\
\hline $\begin{array}{l}\text { Triacylglycerol }^{\mathrm{a}} \\
(\mathrm{mmol} / \mathrm{l})\end{array}$ & $0.5(0.4-0.7)$ & $0.5(0.4-0.6)$ & $0.6(0.4-0.7)$ & $0.6(0.4-0.7)$ & NS & NS \\
\hline $\begin{array}{l}\text { HDL-cholesterol } \\
(\mathrm{mmol} / \mathrm{l})\end{array}$ & $1.6 \pm 0.4$ & $1.6 \pm 0.3$ & $1.7 \pm 0.4$ & $1.6 \pm 0.4$ & NS & NS \\
\hline CRF (stage) & $4.4 \pm 1.5$ & $3.8 \pm 1.3$ & $7.7 \pm 1.7$ & $6.5 \pm 1.6$ & $<0.0001$ & $<0.0001$ \\
\hline Total PA (cpm) & $875 \pm 221$ & $749 \pm 177$ & $740 \pm 187$ & $614 \pm 169$ & $<0.0001$ & $<0.0001$ \\
\hline $\begin{array}{l}\text { Sedentary activity } \\
(\mathrm{min} / \text { day })\end{array}$ & $462 \pm 60.8$ & $473 \pm 55.5$ & $554 \pm 70.8$ & $586 \pm 59.7$ & $<0.0001$ & 0.0003 \\
\hline Light PA (min/day) & $233 \pm 36.1$ & $237 \pm 36.6$ & $190 \pm 36.8$ & $197 \pm 36.9$ & $<0.0001$ & NS \\
\hline $\begin{array}{l}\text { Moderate and vigorous } \\
\text { PA (min/day) }\end{array}$ & $107 \pm 35.8$ & $81.5 \pm 23.5$ & $102 \pm 32.3$ & $74.9 \pm 28.2$ & NS & $<0.0001$ \\
\hline
\end{tabular}

Data are presented as means \pm SD or as medians (interquartile range)

${ }^{a}$ Logarithmically transformed $\left(\log _{\mathrm{e}}\right)$

$P A$ and $C R F$ PA was assessed by accelerometers (MTI/CSA 7164 Actigraph; Pensacola, FL, USA), which were worn around the hip over 7 days [22]. The sampling time was set at $1 \mathrm{~min}$, and data were included if at least four full days (at least 3 weekdays for $12 \mathrm{~h}$ and one weekend day for $10 \mathrm{~h}$ ) of measurements were available [23]. Fifty per cent of the children wore the accelerometers constantly for the required time period. For these children, waking time was defined as three consecutive values of above $20 \mathrm{cpm}$ with a sum of above $200 \mathrm{cpm}$. This was tested prior to the start of the study. The other $50 \%$ of the children removed the accelerometers before sleeping. The children wore the accelerometers for a mean of $13.4 \mathrm{~h} /$ day during waking hours. Validation studies of the Actigraph in children, based on direct observation, spiroergometry and energy expenditure measured by doubly labelled water, have found the accelerometer to be accurate [23-26]. Total PA was calculated by multiplying the mean number of weekday counts by five and the mean number of weekend counts by 2 and dividing the sum by 7 . This value was then divided by the amount of time the accelerometer was worn and expressed as counts per minute ( $\mathrm{cpm})$. The time ( $\mathrm{min})$ spent engaged in sedentary activity $(<500 \mathrm{cpm})$, in light PA (501-2,000 cpm) and in moderate and vigorous PA $(>2,000 \mathrm{cpm})$ was calculated $[11,13]$. The threshold for the latter was based on its postulated cardiovascular effects, and is equivalent to walking at a speed of about $4 \mathrm{~km} / \mathrm{h} \mathrm{[11].}$

CRF was assessed by an adapted $20 \mathrm{~m}$ shuttle run test $[27,28]$. This validated test measures aerobic capacity and requires the participant to run back and forth over a distance of $20 \mathrm{~m}$ with progressively increasing speed. The initial pace was $8.0 \mathrm{~km} / \mathrm{h}$ and was increased by $0.5 \mathrm{~km} / \mathrm{h}$ every 
minute. Each increase was indicated by a sound [27, 28]. The stage numbers $(\sim 1 \mathrm{~min})$ are reported with a precision of within 0.5 stages [22].

Questionnaires The parents of all the children were asked about their ethnic background, their educational level, their own height and weight, gestational age at birth and the birthweight of their child. Pubertal stage was rated by the children and parents with the help of a sheet showing the pictures of the five Tanner stages and was defined based on breast development for girls and pubic hair for boys [29]. As only one girl reported to be in Tanner stage 5 and a precise classification of the specific Tanner stage beyond stage 1 is difficult by self report, we divided our population into the following two groups of pubertal stage: prepubertal (Tanner stage 1) and pubertal (Tanner stage $\geq 2$ ). Participants reported media use, including the frequency and length of time spent in front of the television, computers or electronic games. The total sleep duration (hours/night) was also assessed by self report.

Nutritional behaviour was assessed by an abbreviated and modified form of the Coronary Artery Risk Development in Young Adults (CARDIA) food frequency questionnaire [22, 30], adapted to assess Swiss nutrition patterns. In addition, parents were asked how frequently their children ate breakfast and how frequently their children ate in fast food restaurants. We assessed the frequency of servings of different foods per week. From these food groups, three subscales were derived using factor analysis with subsequent varimax rotation.

Insulin resistance and clustered metabolic risk score Insulin resistance was estimated by the homeostasis model assessment of insulin resistance (HOMA-IR) [31]. We used a standardised clustered metabolic risk score that included the following continuous variables: hypertension (average of systolic and diastolic blood pressure), fasting insulin, glucose, triacylglycerol, and inverted fasting HDL-cholesterol $[13,14]$. We determined single $z$ scores for each variable and then added them together to derive a clustered metabolic risk score $[13,14]$. As suggested in the literature [13, 14], we calculated the clustered metabolic risk score without the adiposity component to be able to adjust for adiposity as a covariate in our linear regression models.

Statistics Data are summarised as means \pm SD for normally distributed variables and as medians and interquartile ranges for skewed variables, unless stated differently. Variables with a skewed distribution were logarithmically transformed $\left(\log _{\mathrm{e}}\right)$ for all analyses. Differences between age groups and sexes were tested by ANOVA or by $\chi^{2}$ tests, as appropriate.

Using linear regression we assessed which obesity measure was most strongly associated with insulin resis- tance and the clustered metabolic risk score. Associations between measures of PA, CRF and cardiovascular risk factors were assessed using multiple linear regression models, adjusting for the following sociodemographic, peripartal and behavioural lifestyle parameters: age, sex, pubertal status, birthweight adjusted for gestational age [32], parental weight, ethnicity and educational level, nutritional behaviour (subscales from the food frequency questionnaire, regular consumption of breakfast, frequency of visits to fast food restaurants), media use (hours per day), and sleep duration (hours per night). For instances of statistical significance, we included other potential confounders, i.e. CRF, total PA and BMI (not done if these measures were outcome variables). The effect of the neighbourhood environment (i.e. rural vs urban) on CRF, total PA and cardiovascular risk factors was assessed using linear regression analysis while adjusting for the above-mentioned confounding variables.

We tested whether associations were modified by age, pubertal status or sex. Furthermore, we assessed whether effects of sex were modified by age and/or pubertal status. This was done using appropriate interaction terms. Interactions are only mentioned for cases of statistical significance, which was defined as a $p$ value $<0.05$. Analyses were performed using SPSS version 14.0 (SPSS, Chicago, IL, USA) and Intercooled STATA version 9 (STATA, College Station, TX, USA).

\section{Results}

The baseline characteristics of all the participants are shown in Table 1. There were no differences between boys and girls with respect to BMI and most of the cardiovascular parameters. Measures of CRF, PA and media use were higher among the boys.

Of the obesity measures studied, BMI was most strongly related to cardiovascular risk factors and was therefore chosen as the indicator of obesity for further analyses. In a model that included age, sex and pubertal stage, BMI explained $35 \%$ of the variance in HOMA-IR and $30 \%$ of the variance in the metabolic risk score and remained significant after adjusting for the sum of four skinfold thicknesses (explaining $33 \%$ and $29 \%$ of the respective variances) or waist circumference (explaining 30\% and $28 \%$ of the respective variance; all $p \leq 0.003$ ).

The correlations between CRF and measures of PA were weak and found to be strongest for total or moderate and vigorous PA $(r=0.11$ and $r=0.14$, respectively, after adjustment for age, sex and pubertal status; both $p<0.001)$.

Associations of CRF and PA with cardiovascular risk factors $\mathrm{CRF}$, total PA and time spent in moderate and 
vigorous PA showed significant inverse associations with measures of obesity and with HOMA-IR and the metabolic risk score (Table 2). These associations were independent of sociodemographic and other behavioural lifestyle parameters (nutritional behaviour, media use, sleep duration). Specifically, an increase in CRF of one stage in the shuttle run test (equal to $1 \mathrm{~min}$ ), was associated with an $8 \%$ reduction in the sum of four skinfold thicknesses and a $6 \%$ reduction in HOMA-IR. Sedentary activity was positively associated with the metabolic risk score, whereas light PA was inversely associated with this score. All these relationships persisted after further adjustment for BMI (data not shown).

The associations of CRF with measures of obesity and cardiovascular risk factors were independent of total PA (BMI: $\beta=-0.02,95 \% \mathrm{CI}-0.03$ to $-0.01, p<0.001$; sum of four skinfold thicknesses: $\beta=-0.09,95 \%$ CI -0.11 to -0.07 , $p<0.001$; HOMA-IR: $\beta=-0.07,95 \% \mathrm{CI}-0.10$ to -0.03 , $p<0.01$; metabolic risk score: $\beta=-0.05,95 \%$ CI -0.08 to $-0.01, p<0.05)$. Similarly, the associations of total PA and sedentary activity with the sum of four skinfold thicknesses persisted after adjusting for CRF $(\beta=-0.02,95 \% \mathrm{CI}-0.04$ to $-0.003, p<0.05 ; \beta=0.008,95 \%$ CI 0.003 to $0.01, p<0.01$, respectively), as did those of total PA, light PA and sedentary PA with the metabolic risk score $(\beta=-0.09,95 \%$ CI -0.11 to $-0.07, p<0.001 ; \beta=-0.09,95 \%$ CI -0.11 to -0.07 , $p<0.001 ; \beta=-0.09,95 \%$ CI -0.11 to $-0.07, p<0.001$, respectively). The few interactions of the exposure variables with age are shown in Table 2.

CRF, PA, cardiovascular risk factors and the neighbourhood environment Approximately half of the study population $(n=245)$ were living in a rural environment. CRF and total PA were higher in children living in a rural environment as compared with children living in an urban environment, independent of sociodemographic and behavioural lifestyle confounder variables (Table 3). Children living in a rural area spent 14 more minutes per day engaged in light PA and eight more minutes per day doing moderate and vigorous PA, while there was no difference between the two groups with respect to the time spent on sedentary activities. CRF was 0.5 stages higher in the children living in a rural area, which corresponded to a $12 \%$ difference among those in the first grade and a 7\% difference among those in the fifth grade. Adjusting for BMI did not change the relationship between the neighbourhood environment and CRF or total PA (data not shown).

BMI and skinfold thickness did not differ between the two groups $(p=\mathrm{NS})$, but the rural group had much lower values for cardiovascular risk factors (Table 3). These risk differences remained unchanged after further adjustment for CRF, total PA and BMI (HOMA-IR: $\beta=-0.35,95 \% \mathrm{CI}-0.51$ to $-0.18, p<0.001$; metabolic risk score: $\beta=-0.39,95 \%$ CI -0.59 to $-0.20, p<0.001)$.

There was no indication of confounding or modification of the effect of CRF or PA on cardiovascular risk factors or obesity by the neighbourhood environment (data not shown).

\section{Discussion}

In this paper we show that reduced CRF and PA were independently and separately associated with obesity, insulin resistance and the metabolic risk score in randomly selected healthy urban and rural schoolchildren. Living in an urban area was associated with lower PA, reduced CRF

Table 2 Adjusted associations of CRF and measures of PA with cardiovascular risk parameters

\begin{tabular}{|c|c|c|c|c|c|}
\hline \multirow[t]{2}{*}{ Cardiovascular risk factor } & \multirow[t]{2}{*}{ CRF (stage) } & \multicolumn{4}{|l|}{ PA } \\
\hline & & $\begin{array}{l}\text { Total (per } \\
100 \mathrm{cpm})\end{array}$ & $\begin{array}{l}\text { Sedentary } \\
\text { (per } 10 \mathrm{~min} \text { ) }\end{array}$ & $\begin{array}{l}\text { Light (per } \\
10 \mathrm{~min})\end{array}$ & $\begin{array}{l}\text { Moderate and vigorous } \\
\text { (per } 10 \mathrm{~min} \text { ) }\end{array}$ \\
\hline $\mathrm{BMI}^{\mathrm{e}}\left(\mathrm{kg} / \mathrm{m}^{2}\right)$ & $\begin{array}{c}-0.02(-0.03 \\
\text { to }-0.01)^{\mathrm{c}}\end{array}$ & $\begin{array}{l}-0.005(-0.01 \\
\text { to } 0.005)\end{array}$ & $\begin{array}{l}0.001(-0.002 \\
\text { to } 0.004)\end{array}$ & $\begin{array}{l}0.002(-0.003 \\
\text { to } 0.008)\end{array}$ & $\begin{array}{l}-0.001(0.007 \\
\text { to } 0.006)\end{array}$ \\
\hline $\begin{array}{l}\text { Sum of four skinfold } \\
\text { thicknesses } \\
\end{array}$ & $\begin{array}{r}-0.08(-0.10 \\
\text { to }-0.05)^{\mathrm{c}, \mathrm{d}}\end{array}$ & $\begin{array}{l}-0.03(-0.06 \\
\text { to }-0.005)^{\mathrm{b}, \mathrm{d}}\end{array}$ & $\begin{array}{l}0.006(-0.002 \\
\text { to } 0.01)\end{array}$ & $\begin{array}{l}-0.005(-0.02 \\
\text { to } 0.001)\end{array}$ & $\begin{array}{l}-0.02(-0.03 \\
\text { to }-0.001)^{\mathrm{a}, \mathrm{d}}\end{array}$ \\
\hline HOMA-IR ${ }^{\mathrm{e}}$ & $\begin{array}{c}-0.06(-0.09 \\
\text { to }-0.02)^{\mathrm{b}}\end{array}$ & $\begin{array}{r}-0.05(-0.10 \\
\text { to }-0.005)^{\mathrm{a}}\end{array}$ & $\begin{array}{l}0.01(-0.003 \\
\text { to } 0.02)\end{array}$ & $\begin{array}{l}-0.005(-0.03 \\
\text { to } 0.02)\end{array}$ & $\begin{array}{r}-0.03(-0.06 \\
\text { to }-0.002)^{\mathrm{a}}\end{array}$ \\
\hline Metabolic risk score & $\begin{array}{r}-0.05(-0.09 \\
\text { to }-0.007)^{\mathrm{a}}\end{array}$ & $\begin{array}{c}-0.07(-0.12 \\
\text { to }-0.01)^{\mathrm{a}}\end{array}$ & $\begin{array}{l}0.02(0.001 \\
\text { to } 0.03)^{\mathrm{a}}\end{array}$ & $\begin{array}{r}-0.03(-0.06 \\
\text { to }-0.002)^{\mathrm{a}}\end{array}$ & $\begin{array}{r}-0.04(-0.07 \\
\text { to }-0.004)^{\mathrm{a}}\end{array}$ \\
\hline
\end{tabular}

Data are presented as $\beta$-coefficients (95\% CIs)

Data were adjusted for sociodemographic factors (age, sex, pubertal status, birthweight adjusted for gestational age, parental weight, ethnicity and educational level) and for other behavioural parameters (nutritional behaviour [three subscales from a food frequency questionnaire, regular breakfast intake, frequency of fast-food restaurant visits], media use [hours per day] and sleep duration [hours per night])

${ }^{\mathrm{a}} p<0.05,{ }^{\mathrm{b}} p<0.01,{ }^{\mathrm{c}} p<0.001 ;{ }^{\mathrm{d}}$ interaction with age: $p<0.05$

${ }^{\mathrm{e}}$ Logarithmically transformed $\left(\log _{\mathrm{e}}\right)$ 
Table 3 Adjusted associations ( $\beta$-coefficients with 95\% CI) of living in a rural vs urban environment with CRF, measures of PA and with cardiovascular risk factors

\begin{tabular}{|c|c|c|c|c|c|c|c|}
\hline \multirow[t]{2}{*}{ Parameter } & \multirow[t]{2}{*}{ CRF (stage) } & \multicolumn{4}{|l|}{ PA } & \multirow[t]{2}{*}{ HOMA-IR ${ }^{\mathrm{d}}$} & \multirow{2}{*}{$\begin{array}{l}\text { Metabolic } \\
\text { risk score }\end{array}$} \\
\hline & & $\begin{array}{l}\text { Total } \\
\text { (cpm) }\end{array}$ & $\begin{array}{l}\text { Sedentary } \\
\text { (min/day) }\end{array}$ & $\begin{array}{l}\text { Light } \\
\text { (min/day) }\end{array}$ & $\begin{array}{l}\text { Moderate and } \\
\text { vigorous (min/day) }\end{array}$ & & \\
\hline $\begin{array}{l}\text { Living in a rural vs } \\
\text { urban environment }\end{array}$ & $\begin{array}{r}0.47(0.12 \\
\text { to } 0.83)^{\mathrm{b}}\end{array}$ & $\begin{array}{l}54(7.2 \\
\text { to } 100)^{\mathrm{a}}\end{array}$ & $\begin{array}{l}-10(-30 \\
\text { to } 10)\end{array}$ & $\begin{array}{l}14(1.6 \\
\text { to } 26)^{\mathrm{a}}\end{array}$ & $8.0(0.27 \text { to } 16)^{\mathrm{a}}$ & $\begin{array}{c}-0.29(-0.44 \\
\text { to }-0.14)^{\mathrm{c}}\end{array}$ & $\begin{array}{r}-0.34(-0.52 \\
\text { to }-0.16)^{\mathrm{c}}\end{array}$ \\
\hline
\end{tabular}

Data are presented as $\beta$-coefficients $(95 \%$ CIs)

Data were adjusted for sociodemographic factors (age, sex, pubertal status, birthweight adjusted for gestational age, parental weight, ethnicity and educational level) and for other behavioural parameters (nutritional behaviour [three subscales from a food frequency questionnaire, regular breakfast intake, frequency of fast food restaurant visits], media use [hours per day] and sleep duration [hours per night])

${ }^{\mathrm{a}} p<0.05,{ }^{\mathrm{b}} p<0.01,{ }^{\mathrm{c}} p<0.001$

${ }^{\mathrm{d}}$ Logarithmically transformed $\left(\log _{\mathrm{e}}\right)$

and with an increase in insulin resistance and the metabolic risk score. This observed increase in cardiovascular risk markers persisted after adjustment for CRF, measured PA and BMI.

In our cohort, the relationship between CRF and measures of PA with obesity and cardiovascular risk factors persisted after adjustment for other relevant lifestyle parameters, such as media use [7,14]; nutritional variables such as not consuming breakfast, frequency of visits to fast food restaurants and general nutritional behaviour (food frequency) [5, 33]; and sleep duration [4]. This observation underlines the independent effects of PA and CRF on metabolic risk factors. In accordance with other recent observations, these effects also persisted after adjustment for BMI $[8,11-14]$. This implies that, even in healthy children, CRF and PA can have an effect on cardiovascular risk factors that goes beyond reducing obesity.

Measures of obesity and cardiovascular risk factors were positively associated with sedentary activity and inversely associated with CRF, total PA and time spent engaged in moderate and vigorous PA as well time spent doing light PA. This suggests that even light PA or less sedentary activity might be beneficial for decreasing cardiovascular risk. The associations between CRF and measures of PA were weak, but similar to those reported previously by other authors [13]. The effects of CRF and total PA on metabolic risk were not independent of each other in a study on 9- to 10-year-old Danish children [34], but were completely independent of each other in a large European study with a population consisting of 9- and 15-year-old children [13]. This observation led to the notion that CRF and PA influence metabolic risk through different pathways or that CRF is a marker of specific muscle characteristics [13]. In our population we replicated the findings of the latter European study. We therefore assume that PA has an independent beneficial effect, regardless of whether CRF is increased. This is of substantial importance for interventions in public health, as it may be easier to implement an increase in total or light PA or a decrease in sedentary activity than to increase CRF.

Some recent studies have highlighted the relationship between the neighbourhood environment and PA in children [18-21]. The PA levels of young children and adolescents were associated with the amount of green space and parks and with the general impression of 'activityfriendliness' in the neighbourhood [18-20]. However, these studies either examined small study populations or did not use objective measures of PA. The novel findings of our study are that children living in an urban environment were less physically active (as assessed by accelerometers), had lower values of CRF and higher values for cardiovascular risk factors compared with children living in rural areas. This association was not explained by sociodemographic variables, other lifestyle behavioural parameters, or the children's BMI. Intriguingly, the increases in insulin resistance and the metabolic risk score remained unchanged after adjustment for the observed differences in PA or CRF. This could be related to a bias introduced by the high intraindividual variability of PA or the inability of accelerometers to capture certain activities, such as cycling, that might be more prevalent in rural areas. Yet, this explanation is less convincing for CRF. Although we adjusted for various potential confounding factors, we may not have accounted for all of them. It is, nevertheless, reassuring that we obtained the same findings in several more homogeneous subpopulations, e.g. in prepubertal children or in children of Swiss origin (results not shown). Other potential explanations are that the urban children were more frequently exposed to ambient air pollution including fine particles. This may have led to systemic increases in inflammatory mediators $[35,36]$ and, in turn, to an increase in insulin resistance and the metabolic risk score. However, as our results are new and raise several new research questions, they should first be replicated in a further study focusing on the different aspects of the neighbourhood environment. 
The present study is subject to some limitations. Owing to its cross-sectional design, we cannot infer that our observed associations reflect causal relationships. Moreover, our study is observational. Yet, it is difficult to assess the influence of the neighborhood environment in a randomised controlled study. Another limitation is related to the measures of PA and CRF. We objectively measured PA for 1 week in most of the children. Although the majority of other studies have assessed PA over a shorter period of 3-4 days [11, 14, 34], 1 week may not be sufficient to reliably indicate a child's true average activity level. However, this error is mostly random and therefore tends to lead to an underestimation of the true effect of activity. $\mathrm{CRF}$ is less variable than PA and is therefore used as a surrogate of PA. To assess CRF, we used the $20 \mathrm{~m}$ shuttle run. Compared with a bicycle test, this test could penalise obese children, as the shuttle run test is a weight-bearing activity. This could lead to an overestimation of the relationship between CRF and obesity measures or cardiovascular risk factors. However, analysis of the same relationships in children of normal weight did not alter our results (data not shown). In addition, the associations between the shuttle run test and outcome measures were not modified by weight status (data not shown). The strengths of the study are the random selection of the study population, the high participation rate of $94 \%$, consideration of important behavioural confounder parameters and the inclusion of novel explanatory factors (neighbourhood environment).

In summary, we found that, in a population-based sample of schoolchildren, reduced CRF and PA were associated with obesity and an increase in insulin resistance and the metabolic risk score, independently of each other, sociodemographic and nutritional parameters, media use and sleep duration. Because of the independent and separate associations of PA with metabolic risk factors, PA may reduce cardiovascular risk regardless of CRF. These findings could have substantial public health implications, as it may be easier to increase PA than CRF. Based on our results, being fit or physically active may not only reduce obesity, but also decrease metabolic risk markers by effects that go beyond simply reducing obesity.

Living in an urban area was independently associated with lower PA, decreased CRF and increases in insulin resistance and the metabolic risk score, regardless of CRF, total PA and BMI. Thus several strategies aimed at improving cardiovascular health in children, each with a different target parameter, such as increasing CRF or PA or adapting the neighbourhood environment could be employed in parallel.

Acknowledgements We thank all the children, parents and teachers who volunteered to participate in this study. We thank U. Keller for the helpful discussions, and U. Dürring, U. Schild and V. Wyss (Division of Endocrinology, Diabetes and Clinical Nutrition, University of Basel) for their competent assistance in collecting, transporting and centrifuging the blood samples, respectively. We thank D. Crook from the University of Lausanne for the careful review of the manuscript.

We appreciate the help of the assistants based at the Institute of Exercise and Health Sciences in Basel. This study was supported by the Federal Office of Sports (Magglingen, Switzerland), the Swiss National Science Foundation (grant nos 3234-069271 and PMPDB114401) and the Diabetes Foundation of the Region of Basel.

Duality of interest The authors declare that there is no duality of interest associated with this manuscript.

\section{References}

1. Wang Y, Lobstein $\mathrm{T}$ (2006) Worldwide trends in childhood overweight and obesity. Int J Pediatr Obes 1:11-25

2. Srinivasan SR, Myers L, Berenson GS (2002) Predictability of childhood adiposity and insulin for developing insulin resistance syndrome (syndrome $\mathrm{X}$ ) in young adulthood: the Bogalusa Heart Study. Diabetes 51:204-209

3. Raitakari OT, Juonala M, Kahonen M et al (2003) Cardiovascular risk factors in childhood and carotid artery intima-media thickness in adulthood: the Cardiovascular Risk in Young Finns Study. JAMA 290:2277-2283

4. Reilly JJ, Armstrong J, Dorosty AR et al (2005) Early life risk factors for obesity in childhood: cohort study. BMJ 330:1357

5. Rampersaud GC, Pereira MA, Girard BL, Adams J, Metzl JD (2005) Breakfast habits, nutritional status, body weight, and academic performance in children and adolescents. J Am Diet Assoc 105:743-760

6. Nicklas TA, Demory-Luce D, Yang SJ, Baranowski T, Zakeri I, Berenson G (2004) Children's food consumption patterns have changed over two decades (1973-1994): The Bogalusa Heart Study. J Am Diet Assoc 104:1127-1140

7. Robinson TN (1999) Reducing children's television viewing to prevent obesity: a randomized controlled trial. JAMA 282:15611567

8. Eisenmann JC, Katzmarzyk PT, Perusse L, Tremblay A, Despres JP, Bouchard C (2005) Aerobic fitness, body mass index, and CVD risk factors among adolescents: the Quebec family study. Int J Obes (Lond) 29:1077-1083

9. Ness AR, Leary SD, Mattocks C et al (2007) Objectively measured physical activity and fat mass in a large cohort of children. PLoS Med 4:e97

10. Riddoch C, Boreham C (2000) Physical activity, fitness and children's health: current concepts. In: Armstrong N, van Mechelen W (eds) Paediatric exercise science and medicine. Oxford University Press, Oxford, pp 243-252

11. Andersen LB, Harro M, Sardinha LB et al (2006) Physical activity and clustered cardiovascular risk in children: a cross-sectional study (The European Youth Heart Study). Lancet 368:299-304

12. Kelishadi R, Razaghi EM, Gouya MM et al (2007) Association of physical activity and the metabolic syndrome in children and adolescents: CASPIAN Study. Horm Res 67:46-52

13. Ekelund U, Anderssen SA, Froberg K, Sardinha LB, Andersen LB, Brage S (2007) Independent associations of physical activity and cardiorespiratory fitness with metabolic risk factors in children: the European youth heart study. Diabetologia 50:18321840

14. Ekelund U, Brage S, Froberg $\mathrm{K}$ et al (2006) TV viewing and physical activity are independently associated with metabolic risk in children: the European Youth Heart Study. PLoS Med 3: 0476-0484 
15. Lee CD, Blair SN, Jackson AS (1999) Cardiorespiratory fitness, body composition, and all-cause and cardiovascular disease mortality in men. Am J Clin Nutr 69:373-380

16. Manini TM, Everhart JE, Patel KV et al (2006) Daily activity energy expenditure and mortality among older adults. JAMA 296:171-179

17. Summerbell CD, Waters E, Edmunds LD, Kelly S, Brown T, Campbell KJ (2005) Interventions for preventing obesity in children. Cochrane Database Syst Rev CD001871

18. Cohen DA, Ashwood JS, Scott MM et al (2006) Public parks and physical activity among adolescent girls. Pediatrics 118:e1381e1389

19. de Vries SI, Bakker I, van Mechelen W, Hopman-Rock M (2007) Determinants of activity-friendly neighborhoods for children: results from the SPACE study. Am J Health Promot 21:312-316

20. Roemmich JN, Epstein LH, Raja S, Yin L, Robinson J, Winiewicz D (2006) Association of access to parks and recreational facilities with the physical activity of young children. Prev Med 43:437-441

21. Kelishadi R, Ardalan G, Gheiratmand R et al (2007) Association of physical activity and dietary behaviours in relation to the body mass index in a national sample of Iranian children and adolescents: CASPIAN Study. Bull World Health Organ 85:19-26

22. Zahner L, Puder JJ, Roth R et al (2006) A school-based physical activity program to improve health and fitness in children aged 6 13 years (Kinder-Sportstudie KISS): study design of a randomized controlled trial [ISRCTN15360785]. BMC Public Health 6:147

23. Freedson P, Pober D, Janz KF (2005) Calibration of accelerometer output for children. Med Sci Sports Exerc 37:S523-S530

24. Montgomery C, Reilly JJ, Jackson DM et al (2004) Relation between physical activity and energy expenditure in a representative sample of young children. Am J Clin Nutr 80:591-596

25. Ekelund U, Sjostrom M, Yngve A et al (2001) Physical activity assessed by activity monitor and doubly labeled water in children. Med Sci Sports Exerc 33:275-281
26. Janz KF (1994) Validation of the CSA accelerometer for assessing children's physical activity. Med Sci Sports Exerc 26:369-375

27. Leger LA, Mercier D, Gadoury C, Lambert J (1988) The multistage 20 metre shuttle run test for aerobic fitness. J Sports Sci 6:93-101

28. van Mechelen W, Hlobil H, Kemper HC (1986) Validation of two running tests as estimates of maximal aerobic power in children. Eur J Appl Physiol Occup Physiol 55:503-506

29. Duke PM, Litt IF, Gross RT (1980) Adolescents' self-assessment of sexual maturation. Pediatrics 66:918-920

30. McDonald A, Van Horn L, Slattery M et al (1991) The CARDIA dietary history: development, implementation, and evaluation. J Am Diet Assoc 91:1104-1112

31. Matthews DR, Hosker JP, Rudenski AS, Naylor BA, Treacher DF, Turner RC (1985) Homeostasis model assessment: insulin resistance and beta-cell function from fasting plasma glucose and insulin concentrations in man. Diabetologia 28:412-419

32. Prader A, Largo RH, Molinari L, Issler C (1988) Physical growth of Swiss children from birth to 20 years of age. Helv Paediatr Acta Suppl 52:1-125

33. Pereira MA, Kartashov AI, Ebbeling CB et al (2005) Fast-food habits, weight gain, and insulin resistance (the CARDIA study): 15-year prospective analysis. Lancet 365:36-42

34. Brage S, Wedderkopp N, Ekelund U et al (2004) Features of the metabolic syndrome are associated with objectively measured physical activity and fitness in Danish children: the European Youth Heart Study (EYHS). Diabetes Care 27:2141-2148

35. Calderon-Garciduenas L, Villarreal-Calderon R, Valencia-Salazar $\mathrm{G}$ et al (2008) Systemic inflammation, endothelial dysfunction, and activation in clinically healthy children exposed to air pollutants. Inhal Toxicol 20:499-506

36. O'Neill MS, Veves A, Sarnat JA et al (2007) Air pollution and inflammation in type 2 diabetes: a mechanism for susceptibility. Occup Environ Med 64:373-379 